\title{
British Producing Germanium From Flue Dust
}

B RITISH success in extracting significant quantities of germanium from gas works' flue dusts has been one of the prime forces in promoting similar research in the United States. Pittsburgh Consolidation Coal Co. and Pennsylvania Coal \& Coke Co. are two of the larger U. S. firms with germanium from flue dust research programs.

British interest in germanium started in 1933 when V. M. Goldschmidt reported that some coals from the Yard Seam of Northumberland and Durham contained 30 to $50 \mathrm{ppm}$ of germanium.

However, in a recent survey of all the United Kingdom's major coalfields by the Fuel Research Station of the Dept. of Scientific and Industrial Research, it was found that Goldschmidt's estimate was rather high. Ten samples of coal taken from the seam he investigated showed germanium content of 2 to $22 \mathrm{ppm}$ with an average content of about $7 \mathrm{ppm}$. It appears that germanium occurs in all the major coalfields and is not localized in a few seams.

The germanium may be associated with carbonaceous material in the coal rather than with another mineral. It is believed that this is partly the reason that germanium is likely to be found in the flues of producer plants rather than in flues from ovens where coal is initially carbonized. Dry coal ash produced from dirty coals have shown an average germanium content of 0.006 pct, while clean coal ash averaged about 0.013 pct.

About 12 times the amount of germanium will be found in flue dust in comparison to ash. The amount of germanium produced from dirty and clean coals should be 0.072 pct and 0.156 pct respectively on the average. The difference between flue dust and ash may be even greater because deposits of flue dusts have been found to contain up to 2 pct germanium.

Generally, it has been found that germanium content of dust in the $\mathrm{CO}_{2}$ flue and in the waste heat boiler area is greater than germanium content of dust from the $\mathrm{CO}$ flue. However, flue dust at the South Metropolitan Gas Co. plant was found to have a higher germanium content than that from around the waste heat boiler. Majority of Britain's large gas works have been surveyed for germanium bearing flue dust and are contributing their outputs to the nation's supply of germanium metal.

Johnson Mathey \& Co. Ltd. considered a number of processes before deciding to investigate a metallurgical method. The firm hopes to attain an output of about $350 \mathrm{~kg}$ annually using flue dust from producer plants as raw material.

The initial step in germanium extraction from flue dust is smelting the dust with known collectors. Iron, nickel, and copper are suitable collectors for germanium, while copper is used for gallium collection. Flue dust is smelted with soda and lime as fluxes for the silica and alumina and with copper oxide and carbon to provide copper for the collec-

This is an abstract of an article on Production and Uses of Germanium by J. A. Gay, that appeared in the June 1953 issue of Chemical \& Process Engineering, published by Leonard Hill Ltd., London. tion of the germanium and gallium. The copper-iron regulus obtained contains more than 90 pct of the germanium and 80 pet of the gallium.

Dusts high in sulphate were given a preliminary roasting to reduce sulphur content to 5 pct. This avoided the excessive formation of matte, which by taking up the copper, reduced the amount of gallium extracted into the regulus. The regulus contains about 3 to 4 pet germanium, and usually 90 to 95 pet of the available germanium is extracted. Most of the lost germanium is deposited in the flue of the furnace being used. The flue is regularly cleaned and the dust returned for processing.

To recover rare elements from the regulus, it is first converted into a solution of trichlorides. All the germanium, with some of the arsenic is recovered from the solution by distillation. Most economical method is to treat the regulus with a current of chlorine under a dilute solution of ferric chloride, which acts as a catalyst. Because the process is highly exothermic and could be applied cold without use of external heat, the rate of reaction is controlled by the rate chlorine is added to the system.

The resulting chloride solution was siphoned or blown into a battery of Pyrex stills heated by electric mantles. Vapors pass through standard Pyrex containers and the condensates flowed through a common pipeline to a Pyrex receiver. This was also connected through an empty carboy serving as a trap to a water-filled carboy collecting and hydrolizing noncondensed vapors of arsenic and germanium chlorides.

Distillation is started by slowly dropping sufficient concentrated sulphuric acid into the boiling solution to liberate enough hydrochloric acid to render the solution in the still about $7 \mathrm{~N}$ with respect to the acid. Distillation is continued until about 25 pct of the still content is evaporated. Under these conditions the acidity of the condensate is such that it is separated into two layers. The lower layer consists of germanium tetrachloride containing up to 20 pct of arsenic trichloride and the upper layer consists of constantly boiling hydrochloric acid containing arsenic trichloride almost free of germanium.

The crude germanium tetrachloride, with a boiling point of $84^{\circ} \mathrm{C}$, is separated from arsenic trichloride by careful fractional distillation. Prolonged refluxing of the liquid through a column packed with clean copper turnings is the most satisfactory way of eliminating the residual arsenic.

After refluxing for 12 to $15 \mathrm{hr}$, pure germanium containing less than 1 part arsenic in $10^{7}$ germanium was obtained. The chloride was hydrolized to dioxide and washed free from hydrochloric acid and dried at $150^{\circ} \mathrm{C}$. To produce germanium metal the oxide is placed in a pure graphite boat and heated in a tube furnace in hydrogen to about $650^{\circ} \mathrm{C}$. At $650^{\circ} \mathrm{C}$ the hydrogen is replaced with pure nitrogen and temperature raised to $1000^{\circ} \mathrm{C}$ to melt the previously formed powder into an ingot. An ingot molded in a hydrogen atmosphere becomes porous on cooling because molten germanium absorbs hydrogen liberated during solidification, producing minute blowholes. 